\title{
Reticence to Speak English: Lived Experiences of the Teacher Education Students
}

\author{
Shelly Joy S. Jungco, Audrey Karyl P. Maligang, Lennie S. Malubay, Mary Jane V. Esimos \\ Northern Iloilo Polytechnic State College, Estancia, Iloilo, Philippines
}

\begin{abstract}
The purpose of this study was to was to investigate the lived-experiences of the Teacher Education students of the Northern Iloilo Polytechnic State College, Estancia, Iloilo, Philippines in terms of being reticent to speak English. Specifically, the study explored the following research questions: what are the livedexperiences of students in terms of being reticent to speak English? and what insights and meaning to Teacher Education students' reticence to speak English may be revealed by their lived experiences? This study used the qualitative research design, particularly the phenomenological research approach. Themes and eidetic insights were established to describe the lived experiences of the students and the recommendations were also made by the researcher. The themes presented in this study were: (1) Low proficiency in the target language. (2) Silence as an innate characteristic. (3) Unwillingness to communicate due to shyness and fears. (4) A need for a formation of a speaking habit. (5) Reluctant to speak due to difficulty in pronunciation. (6) A need for focus and memory exercise. (7) A need for waittime to speak their minds. (8) Perceived reticence in the classroom: a need for proper conditioning. It can be noted that students' reticence to speak English were due to the following reasons: low level of English proficiency, shyness, fears, pronunciation difficulty, poor speaking habit, poor memory, innate characteristic, and poor focus. However, there exists an eidetic insight that the students' reticence can be reduced by means of teacher's strategies and use of classroom activities to develop their oral fluency and participation.
\end{abstract}

Keywords: experiences, reticence, phenomenology, communication skills, silence, language anxiety

\section{Introduction}

Communication is an important part in daily life. One needs to communicate in order to understand and to be understood. Students are expected to communicate their ideas during discussion with teachers in order to learn. Communications skills, however, should be enhanced and mastery of the language should be possessed.

Nevertheless, the fact remains that language learning is an extremely complex process, and it is further complicated by the learners' individual differences and their different social, political and cultural background.

Because language learning is difficult, many students fail to communicate their ideas competently. Most often, students can hardly express themselves in English, while others refuse to talk at all.

According to Li and Liu (2011), among all sorts of classroom phenomena, the most frustrating one is that students will not or cannot actively participate in group discussions. Students ${ }^{\text {ee }}$ reticence, withdrawal, or fear of interacting not only deprives of them sharing what they know, but also deprives the teacher and classmates of benefiting from it. Student oral participation in English has been an issue which most English teachers would like to address.

Reticent individuals refer to those who view themselves as incompetent communicators, and measured against norms about appropriate levels of talkativeness in social situations ( $\mathrm{Li}$ and $\mathrm{Liu}, 2011$ ). According to Tong (2010), students are expected to be involved in interactive and co-operative learning tasks.

By way of observation, Filipino students seem passive and reticent, especially in English classes. Some rarely respond to their teachers or actively participate in discussions. Reticence to speak English is a phenomenon. It is a serious problem of students which needs to be 
addressed by a teacher. Speaking or communicating is a must for the Teacher Education students of the Northern Iloilo Polytechnic State College since they are future teachers or educators. However, there are many of them who are not only proficient in English but are reluctant to speak in English as well. This is a common and perennial problems and complaints of most teachers.

From the premise that reticence is a communication problem (Keaten \& Kelly 2000) and that reticent individuals tend to avoid communication in social and public contexts and at the same time view themselves as incompetent communicators, the researcher became interested to determine and examine the day-to-day lived experiences of the selected students of the Teacher Education Department as reticent individuals. Thus, this study is conceptualized.

\section{Objectives}

The purpose of this study was to investigate the lived-experiences of the Teacher Education students of the Northern Iloilo Polytechnic State College, Estancia, Iloilo, Philippines in terms of being reticent to speak English.

Specifically, the study explored the following research questions:

1. What are the lived- experiences of students in terms of being reticent to speak English?

2. What insights and meaning to Teacher Education students' reticence to speak English may be revealed by their lived experiences?

\section{Literature Review}

Research findings indicate that many Asian students are unwilling to be engaged in oral activities in English lessons.

In the study of Jackson and Liu (2008) on Chinese EFL students' reticence at varied proficiency levels stated that clearly reticence is a serious and common phenomenon in English-language classes across all levels in the Mainland Chinese institution. Despite their willingness and positive attitude, few students were observed to respond actively to the teacher in class, especially when the questions were difficult and/or challenging.

In the study conducted by Donald (2010) which investigated reticence in the ESL classroom concluded that there is no definitive cause of reticence in the classroom, which makes the issue problematic for the practitioner when attempting to elicit response from learners. Cultural beliefs regarding learning and the role of the teacher, fear of being misunderstood on the part of the learner and the fear of losing face are some of the factors of students' reticence in the ESL classroom.

In his examination of the ethics of student classroom silence, Li and Liu (2001) mentioned that low selfesteem, fear of being ridiculed, fear of giving wrong responses, cultural differences, avoidance of conflict, and communication apprehension are the reasons why the students are reticent to participate.

In the case study conducted by Tong (2008) as he investigated Hongkong junior students' oral participation behavior in English classrooms found that while students were quiet and passive at the beginning of the fieldwork period, students were ready to express their own opinions at some other time. The findings also suggest that Asian students' quietness and willingness to communicate orally can be attributed to their language proficiency.

In an empirical study of Task-Based Approach in overcoming classroom reticence (2012), the results showed that students' low English proficiency, lack of motivation, students' characters, the teaching methods and the teacher's role are the main causes of classroom reticence.

In the study conducted by Williams and Andrade (2008) on Foreign Language Learning Anxiety in Japanese EFL University Classes, they found out that anxiety was most often associated with the output or processing stages of the learning process and to the teacher or other people.

In the Ethnographic study on silence in the Chinese EFL Class, Liu (2009) found out with participant observations and ethnographic interviews that students kept silent in class to negotiate face to keep harmonious relationships.

Moreover, the study of Abdul Karim and Ahamad Shah (2002) concluded that classroom participation anxiety partially explains the students' reticent behaviors during classroom hours.

\section{Methods \\ Research Design}


This study used a qualitative phenomenological approach to explore the lived experience of the participants in terms of being reticent to speak English. A phenomenological approach is used to gain a deeper understanding of the nature or meaning of the everyday "lived" experiences of people (Russel and Gregory, 2008; Creswell,2003).

Moustakas (1994; in Finch, 2008)) posited participants could only live their own experiences and put meanings to the experiences; but researchers could listen objectively to the participants' perceptions to discover the meanings and essence of their experiences.

Since this study uses an inquiry method, the researcher was alerted to the "life experiences" and the emergence of themes that brought new insights to reflect on.

\section{Participants of the Study}

The participants directly involved in this study were the 7 regular college students in a state college who were selected using a purposive sampling scheme/technique. Purposive sampling is used in phenomenological research which purposely selects individuals who have experienced the phenomenon. The 7 participants emerged to be the most reticent during the survey, and thus were considered for the in-depth interview. According to Ellis (2016), a sample of between 6 and 20 individuals is sufficient.

\section{Research Instrument}

A researcher-made interview guide was used as the main instrument, and it contains two main simple questions to allow the participant to understand easily, and then express and elaborate their experiences of being reluctant to speak English in the classroom.

\section{Reliability and Validity}

Interviews were audio-taped, transcribed verbatim, and checked for accuracy using two procedures recommended by Creswell (2007) for qualitative research. The first approach used for establishing validation was "member checking" wherein the researcher went back and solicited participants' views of the credibility of the findings, interpretations, and conclusions, so that they can judge the accuracy and credibility of the account.

According to Russel and Gregory (2008), the researcher will have to go back to the participants and inquire whether their viewpoints are faithfully interpreted, to determine whether there are gross errors of fact, and to ascertain whether the account makes sense to participants with different perspectives (Russel and Gregory, 2008).

This was supported by Jenkins (2010), when he said that member checking interviews are conducted to assure accuracy in understanding the perspective of the participants helping to insure credibility in the findings.

Reliability, in qualitative research, refers to the stability of responses. The researcher employed a goodquality voice recorder to capture the details of interview with the participants. An outside evaluator was requested to listen to the tape-recorded interview for reliability of the responses as to checking for clarity of voice, as well as the consistency and accuracy of the participants' responses.

\section{Data Gathering Procedure}

The researcher personally approached the participants and asked for their permission to conduct an in depth, unstructured interview with them. The purpose of the study was thoroughly explained by the researcher, the queries of the participants were answered, and the participants were assured of the confidentiality of their responses.

The interview started with the informal conversation to establish good rapport and to engage an in-depth dialogue with the participants. Proper protocol, tact, and courtesy were properly observed during the interview so as to make the participants comfortable and can freely express their lived-experiences. Each single interview was approximately 45 minutes in duration.

A good voice recorder was utilized to capture the proceedings of the interview for complete and accurate data transcription. The audio-taped interviews were later transcribed for accuracy.

\section{Treatment of the Data and Methods in Analyzing the Lived Experiences}


Data gathered underwent a "sifting" process to get the nucleus of truth about the day-to-day lived experiences by the participants in their writing composition in English.

From the interview questions, a set of primary data initially was available:

a. The participants' recalling of their previous speaking experiences in English classes, specifically the situations that contribute to their reluctance to communicate orally.

b. Their personal lived-experiences in terms of being reticent to speak English.

Data treatment was emic in nature, wherein data were extracted intrinsically from the participants' point of view.

Each participant in a sit-down discussion articulated the challenges in their day-to-day lived experiences in terms of being reticent to speak English.

The researcher set aside their experiences, as much as possible, to take a fresh perspective toward the phenomenon under examination. This is a state of epoche or bracketing (Husserl's concept). Hence, "transcendental" means "in which everything is perceived freshly, as if for the first time" (Moustakas, 1994:34).

In a way, the researcher used probing questions, when the participants gave brief answers, and bracketing to abandon biases and eliminate incidentals.

The responses of each group were reflected upon, to identify common themes by coding and categorizing the essential meaning of the responses. The researcher decided what to select and how to express them in order. The main concern of the researcher was to describe faithfully the responses rather than to explain. According to Creswell (2005; in Finch, 2008), "Qualitative data analysis consists of describing information and developing themes" from research data.

Recurrent themes were identified and emerged during the rereading and interpretation of interview transcripts.

The next stage was to establish the thematic insights, wherein, themes and subthemes were established, specifically on the lived experiences shown by the students in reluctance to speak English. Finally, the researcher delved into the deeper level of examination to achieve eidetic insights or "eidos" or nucleus of truth.

\section{Results and Discussion}

This part of the research paper presents the data of the lived-experiences of students in terms of being reticent to speak English. The experiences are presented in order as they emerged from the text. Significant statements are provided to illustrate the richness of the data and to provide rigor for evaluations. Descriptions of the experiences in terms of being reticent to speak English writing are presented.

The researcher came to know the participants through interviews, journeying with them through listening and observing their lived experiences in terms of being reticent to speak English. The researcher categorized their narrative responses; and the data were processed as follows: thematic insights and eidetic insights.

\subsection{Thematic Insights}

The following are the themes which emerged from the data analysis and are followed in the flow of the discussion: (1) Low proficiency in the target language (2) Silence as an innate characteristic (3) Unwillingness to communicate due to shyness and fears (4) A need for a formation of a speaking habit (5) Reluctant to speak due to difficulty in pronunciation

(6) A need for focus and memory exercise (7) A need for wait-time to speak their minds (8) Perceived reticence in the classroom: a need for proper conditioning.

\section{Low proficiency in the target language}

The participants do not have facility of communication in the English language. Reticent individuals consider themselves as incompetent communicators ( $\mathrm{Li}$ and Liu, 2011). The participants feel that they can hardly express themselves in English, for they have not mastered the art of communication. They grope for words, especially for proper diction. Their inability to put their ideas across is a clear indication that they have no command of the language and they have not mastered the structures or patterns of the language, that is, to put together the words to form ideas or sentences. It was evident that they cannot sustain their thoughts in speaking English. Burgoon et al (1988; in Rao and Dennis, 2000) found that reticent individuals speak 
less often and for shorter durations. The participants' tendency to codeswitch or shift to the mother tongue when speaking also indicates their communication apprehension that when they insist to continue they might be misunderstood. Because of their low level of English proficiency, the participants opted to keep silent sometimes in English classes. English teachers must look into this reality in the classroom and must explore on new strategies to make students speak English and enhance their oral language fluency. On top of that, English teachers must find ways to immerse students to a real communication process.

\section{Silence as an innate characteristic}

It is the choice of one participant to remain quiet in the English classroom. She prefers to sit down, and just keep silent. It is perceived in this instance that the participant's silence emanates from within her. She feels comfortable of her silent and passive attitude despite the given opportunity for her to talk in class. There is, then, a need for a teacher to become discerning of the students' silence in the class. Once passivity or silence is addressed, oral participation is enhanced.

\section{Unwillingness to communicate due to shyness and fears}

The three participants prefer to remain silent at times because of shyness and fear of making mistakes and fear of being ridiculed. The other 4 participants are afraid to speak for no reason but are shy when classmates look at them intently while they speak. Shyness and fears when communicating have something to do with the person's lack of exposure to a speaking situation or activity. This poses a challenge to English teachers to devise communication activities that would help reduce shyness and fears and increase confidence of students. The participants also express their desire to learn to speak English, but the English teacher, who was supposed to be the facilitator of learning, became the "stumbling block" when the teacher began to ridicule the grammar errors committed in presentations.

\section{A need for a formation of a speaking habit}

One of the participants does not get used to speaking English, and this simply means that he lacks the habit of speaking or using the language. In order to become adept in the language, one needs to use it constantly. The best way to learn the language is to use or speak it. Since there is a need for the participant to develop a speaking habit, the teachers must impose an "Always speak English" policy inside the classroom or whenever and wherever necessary.

\section{Reluctant to speak due to difficulty in pronunciation}

The participants find difficulty in pronouncing words or in producing sounds. Speech Communication class may not serve its purpose well to all college students since the pronunciation skills must have been developed in the formative years, that is in the intermediate level. It has something to do with the weak foundation of the student in his early school stage. In this case, the English teachers may not be able to bring out the improvement in the pronunciation of the students, but could let them give a hard try by devising an activity that may give focus to their need.

\section{A need for focus and memory exercise}

The participants had the difficulty of recalling and retrieving information. However, one participant experiences this memory gap due to her stage fright. But just the same, there is a need for the students to focus and enhance their memories. It is then a task of the English teachers to innovate a strategy to develop in the students sharper memories.

\section{A need for wait-time to speak their minds}

The participants could not immediately express their answers due to abrupt and sudden questions without allowing them to prepare in advance. Students, intelligent and poor alike, may stumble on this type of questioning strategy of teachers. In this case, English teachers must be aware of this pitfall in teaching strategy. It is a must that questions must be given first to the class before calling names to answer.

\section{Perceived reticence in the classroom: a need for proper conditioning}

Three of the participants found themselves to be reticent only in the classroom where speaking English is a must or a requirement. They find themselves most talkative during informal conversation with friends outside the class using her mother tongue. It is, therefore, reasonable to say that language learning is 
extremely difficult (Cheng, 2000). Since the 3 participants found that speaking English in class is a complex activity, they needed to be conditioned in order to reduce their reticence in the classroom. However, the language learning of the participants is reinforced with their liking of reading stories in literature. The use of literary pieces in English subjects, not only in Literature, is then helpful to improve their language learning; thus, may also be a way to develop their oral fluency and participation.

\subsection{Eidetic Insights}

Even though the participants found themselves reticent to speak English, they saw English as an essential tool to develop their oral fluency and participation through the use of effective strategies and meaningful activities.

For the participants, they are reticent to speak English because of the following reasons: low level of English proficiency, shyness, fears, pronunciation difficulty, poor speaking habit, poor memory, innate characteristic, and poor focus. Though reticent, they can develop oral fluency and participation if they are immersed in a real communication situation, if there are meaningful speaking or communication activities and teacher's effective strategies in order to reduce shyness, fears, and most importantly reticence and instead, develop in students the confidence, competence, oral fluency and participation.

\section{Conclusion and Recommendations}

Based on the lived- experiences in terms of being reticent to speak English of the Teacher education students, the lived- experiences realized in classroom reticence are the same in nature and essence for them. In fact, there exists an eidetic insight that the students' reticence can be reduced by means of teacher's strategies and use of classroom activities to develop their oral fluency and participation.

This research has shown that the desire of the participants to learn to speak English realize the essence of a goal for self-improvement in order to overcome difficulty in speaking English and reduce reticence. The lived- experiences revealed could also be a venue for the English teachers to innovate strategies in teaching and enhancing speaking and giving positive comments and criticisms, but not to ridicule errors and put students to shame or embarrassment.

Since the study showed that the Teacher Education students experienced reticence to speak English, it is recommended that the English teachers should provide speaking or communication activities that may help reduce students' reticence and develop in them confidence and oral participation in the classroom.

Since the study showed that the students desire to learn to speak English, it is recommended that English teachers should offer positive comments and criticisms, and not to ridicule and place students to embarrassment, so that interest may be sustained and speaking skills may be developed. The study also showed that the students liked stories in literature, it is therefore recommended that English subjects other than literature should use literary pieces or other written articles as reinforcement for students to learn English. Finally, as the findings revealed the need to use of effective strategies and meaningful activities, English teachers should attend related trainings and seminars to upgrade her use of the strategies and to keep her abreast of the latest.

\section{References:}

1. Abdul Karim, N. H. and Ahamad Shah, M.I.(2002). Silence is not golden: Investigating Classroom Participation Anxiety among IIUM students.

1. Cheng, Xioatang (2000).Asian students' reticence revisited. Retrieved from http://elechina.superred.es/cheng.pdf

2. Creswell, J.W. (2003). Research design: Qualitative, quantitative, and mixed methods approaches (2nd ed.) Thousand Oaks, CA. Sage Publications. Walden Educ. 8035

3. Donald, Shayne (2010).Learning How to Speak: Reticence in the ESL Classroom. Retrieved From http://research.ncl.ac.uk/ARECLS/volume7/donald_vol7.pdf

4. Ellis P (2016) Understanding research for Nursing Students (3rd edn). Sage Publications, London

5. Finch, S.M.(2008). A Qualitative Phenomenological Analysis of Modern Communication: Instant Messaging's Importance for Adolescent and Young Adults.UMI Microform 3348681

6. Harris, Lois R. \& Brown, Gavin T.(2010). Mixing interview and questionnaire methods: Practical problems in aligning data. Retrieved from http://pareonline.net/pdf/v15n1.pdf 
7. Jenkins, J.R.(2010). Introduction in order to mediate reticence in the EFL/ESL Classroom. Retrieved from http://www.foreign.nkfust.edu.tw/ezfiles/13/1013/img/919/J13_01B.pdf

8. Kelly, Lynne, et. al.(2002). Family Communication Patterns And the Development of Reticence.

Retrieved from

http://www.unco.edu/keaten/Family\%20Comm\%20and\%20Reticence\%20Article.pdf

9. Knox, Sarah \& Burkard, Allan W. (2009). Qualitative Research Interviews e-Publications @Marquette

10. Li, Hui and Liu, Yuhui (2011). A Brief Study of Reticence in ESL Class

11. Liu, Jing. (2009). An Ethnographic Study on Silence in the Chinese EFL Class of English

a. Linguistic Postgraduates. Retrieved from http://al.comm.louisville.edu/iic/?page_id =315

12. Liu, Meihua (2007). Anxiety in Oral English Classrooms. A Case Study in China. Indonesian Journal of English Language Teaching. Volume 3/Number 1

13. Liu, Mehua \& Jackson, Jane (2006). Reticence in Chinese EFL students at varied proficiency levels. Retrieved from

http://www.thefreelibrary.com/Reticence+in+Chinese+EFL+students+at+varied+proficiency+levels. -a0219012099

14. Marchand, Tim (2010). Steps towards improved participation? An Analysis of classroom talk and the "ladder" of interaction " in the Japanese context. Retrieved fromhttp://www.asian-efljournal.com/Thesis/Thesis-Marchand.pdf

15. Mason, Mark (2010). Sample Size and Saturation in PhD Studies Using Qualitative Interviews Forum Qualitative Sozialforschung / Forum: Qualitative Social Research, 11(3), Art. 8, http://nbnresolving.de/urn:nbn:de:0114-fqs100387.

16. Russel, C.K. and Gregory, D.M.(2008). Evaluation of Qualitative Research Studies. Retrieved from http://ebn.bmj.com/content/6/2/36.full

17. Smith, J. and Osborn, M.(2007). Interpretative Phenomenological Analysis.

18. Tong, Jimmy(2010) Some Observations of Students' Reticent And Participatory Behaviour in Hong Kong English Classrooms. Electronic Journal of Foreign Language Teaching. Retrieved from http://e-flt.nus.edu.sg/

19. Wilen, William (2004).Encouraging reticent students' participation in classroom discussions. Retrieved from www.okcss.org/

20. Williams, K.E. and Andrade, M.R.(2008).Foreign Language Learning Anxiety in Japanese EFL University Classes: Causes, Coping, and Locus of Control. Electronic Journal of Foreign Language Teaching. Vol. 5, No. 2, pp. 181-191. Retrieved from http://e-flt.nus.edu.sg/

21. Xie,Xiaoyan 2009). Why are students quiet? Looking at the Chinese context and beyond. ELT Journal. Retrieved from http://eltj.oxfordjournals.org/ 